\title{
Changes in the immunohistochemical localization of the glycine receptor in the superior olivary complex of adult circling mice
}

\author{
YOUNG-BOK YOO ${ }^{1}$, DHIRAJ MASKEY ${ }^{2}$ and MYEUNG JU KIM ${ }^{1}$ \\ ${ }^{1}$ Department of Anatomy, Dankook University, College of Medicine, Cheonan-si, South Chungcheong 330-714, \\ Republic of Korea; ${ }^{2}$ Department of Anatomy, Nepalese Army Institute of Health Sciences-College of Medicine, \\ Sanobharyang, Kathmandu 10160, Nepal
}

Received November 27, 2014; Accepted September 9, 2015

DOI: $10.3892 / \mathrm{mmr} .2015 .4431$

\begin{abstract}
Circling mice is a mutant model of spontaneous deafness exhibiting degenerated spiral ganglion cells in the cochlea and loss of organ of Corti. The balance between glycinergic inhibition and glutamatergic excitation in the lateral superior olive (LSO) is essential for the detection of interaural level differences. Long term weakening of glycinergic synaptic inhibition in the LSO may lead to the downregulation of synaptic release of glycine in dorsal cochlear nucleus and downregulation of postsynaptic glycine receptor (GlyR) activity in the LSO, which may contribute to hearing loss. The present study utilized an immunohistochemical method to assess changes in GlyR immunoreactivity (IR) and the cell number in the superior olivary complex (SOC) of heterozygote (+/cir) and homozygote (cir/cir) circling mice. A significant decrease in the IR was observed in all nuclei of the SOC of homozygous mice. Loss of GlyR immunoreactive cells and a decrement in cell size was also observed in the homozygotes. A decrease in the GlyR IR in the neurons and neuropils, cell number and size of the cir/cir, may lead to profound changes in inhibitory transmission and the functional properties in the SOC nuclei. Therefore, the functional loss of inhibitory neurotransmitters in the brainstem may result in deafness of adult cir/cir mice.
\end{abstract}

Correspondence to: Dr Dhiraj Maskey, Department of Anatomy, Nepalese Army Institute of Health Sciences-College of Medicine, Bhandarkhal, Sanobharyang, Kathmandu 10160, Nepal

E-mail: dhiraj_mask@yahoo.com

Professor Myeung Ju Kim, Department of Anatomy, Dankook University, College of Medicine, San 29, Cheonan-si, South Chungcheong 330-714, Republic of Korea

E-mail: mjukim99@dankook.ac.kr

Key words: circling mice, glycine receptor, superior olivary complex, lateral superior olive, medial nucleus of trapezoid body

\section{Introduction}

Circling mice (C57BL/6J-cir), an animal model of deafness inherited in an autosomal recessive manner due to spontaneous mutation of non-syndromic recessive deafness family loci has pathogenomic lesions portraying spiral ganglion cell degeneration in the cochlea, empty Rosenthal canal ascribing in severe degeneration of the axons between hair cells and spiral ganglion cells, and loss of organ of Corti (1). Around postnatal day 7 , the circling mice became hyperactive and exhibited head tossing, tail chasing and circling behavior (1). These characteristic behaviors were observed in the homozygote (cir/cir) mice only.

Deafness is known to be associated with alterations in the auditory pathways (2), which may reflect the decrease in synaptic plasticity, marked changes in neurotransmitters, including D-aspartate (3), glycine (4), gamma-amino butyric acid (5), N-Methyl-D-aspartic acid (NMDA), including its receptors (e.g. NMDAR1) (6), and ion channels (7). Additionally, synapse associated proteins, including protein kinases (8), calbindin (9), extracellular signal-related kinase and stress-activated protein kinases (10), may affect auditory functions. Owing to these changes, the imbalances between excitation and inhibition signals critically affect the neuronal response (11) and tonotopic map profile (12).

Glycine is a major inhibitory neurotransmitter in the brainstem and acts through the strychnine-sensitive glycine receptor (GlyR) (13), involved in various fundamental physiological processes (14). Within the brainstem, glycinergic neurotransmission is essential, particularly in the auditory nuclei (15), for several aspects of neuronal function (16) being involved in basic function, including sound localization or lateral inhibition (17). Lateral superior olive (LSO), a major nucleus of superior olivary complex (SOC) receives bilateral innervation and along with medial nucleus of the trapezoid body (MNTB), medial superior olive (MSO) and superior paraolivary nucleus (SPN), is an important part of hearing, since it is at this level in the ascending auditory pathway where binaural processing of sound localization cues initially occur (18). MNTB provides inhibitory input to LSO and imparts sensitivity to interaural intensity differences in LSO cells (19). Marked glycinergic input is also provided to the SPN by MNTB (20), whose neurons display offset responses to pure tones. 
Alteration of the glycinergic synapses in the auditory pathways due to hearing loss by cochlear ablation and middle ear ossicle removal loss has been reported to induce regulatory changes in the synaptic release and uptake of glycine in the brain stem nuclei and GlyR binding $(4,21,22)$. Age-associated hearing loss is also associated with decreased glycine-immunoreactive neurons and puncta (23), and changes in the GlyR subunits (24). A decrease in the GlyR has been reported to lead to improper functioning, particularly in the brainstem region in specific SOC nuclei following deafness $(21,25)$. As glycine is implicated in the deafness-associated decrease in the inhibition in the SOC, understanding its distribution in a deafness model, including circling mice, may further elucidate this.

Inhibitory glycinergic synapses in adult rodents at MNTB-LSO synapses $(21,26)$ release glutamate as the predominant neurotransmitter from birth (27). However, its release in the cir/cir mouse is sustained at a later period of development (28). This sustenance of the glutamatergic transmission in the later period of developing the MNTB-LSO synapse in cir/cir in mature animals (29) may also contribute to changes in the distribution of GlyR in the brainstem region of the cir/cir mice. Previous studies have suggested an activity-dependent deafness-associated decrease in glycine in the $\operatorname{SOC}(21,24)$. A previous study of GlyR immunoreactivity (IR) in circling mice was performed in the LSO nuclei at p16 (28), however, no studies have been reported in the SOC nuclei as a whole. Although GlyR IR appears in all the SOC nuclei except MSO at $\mathrm{p} 8$ in rodents, mature staining is obtained only following p21 (30). Therefore, considering the sustenance of glutamatergic transmission and deafness-associated GlyR decrease with the lack of studies of GlyR IR in the adult circling mice, the present study used immunohistochemical analysis to detect any possible histopathological changes and to compare the GlyR IR, cell number and the cell size in four SOC regions, LSO, SPN, MSO and MNTB, between adult $+/$ cir and cir/cir mice.

\section{Materials and methods}

Animal experimentation. The present study used 10 adult male mice (+/cir, $n=5$; cir/cir, $n=5$; Orientbio, Inc., Daejeon, Korea). All animal procedures were performed according to the NIH guidelines of animal research (31) and were approved by Dankook University Institutional Animal Care and Use Committee, which adheres to the guidelines issued by the Institution of Laboratory of Animal Resources.

Polymerase chain reaction (PCR). PCR analysis was performed to differentiate between the $+/$ cir and cir/cir mice using genomic DNA obtained from mouse tails. The genomic DNA was isolated, according to the manufacturer's instructions (Bioneer, Daejeon, Korea). The cir/cir mouse was identified by the absence of the tmie gene. PCR was performed with primers designed to amplify the exon 1 coding region of the tmie gene (forward: 5'-AGCTGTAGCTCTGAAATCT-3' and reverse: 5'-TCTGGCAGAATGCATGGAGGCT-3'). A total of $100 \mathrm{ng}$ template DNA was used in a final reaction volume of $20 \mu \mathrm{l}$ [10 mM Tris- $\mathrm{HCl}(\mathrm{pH} 9.0), 40 \mathrm{mM} \mathrm{KCl}, 1.5 \mathrm{mM}$ $\mathrm{MgCl}_{2}, 250 \mathrm{mM}$ dNTP, 20 pmol each primer and 1 unit Taq DNA polymerase; Bioneer Corporation, Daejeon, Korea].
PCR was performed in a thermal cycler (C1000TM; Bio-Rad Laboratories, Singapore) in two stages. The first stage consisted of four cycles of denaturation at $96^{\circ} \mathrm{C}$ for $5 \mathrm{~min}$, annealing at $59^{\circ} \mathrm{C}$ for $1 \mathrm{~min}$ and extension at $72^{\circ} \mathrm{C}$ for $1 \mathrm{~min}$. The second stage included 30 cycles of denaturation at $96^{\circ} \mathrm{C}$ for $1 \mathrm{~min}$, annealing at $59^{\circ} \mathrm{C}$ for $1 \mathrm{~min}$ and extension at $72^{\circ} \mathrm{C}$ for $1 \mathrm{~min}$, followed by a final extension at $72^{\circ} \mathrm{C}$ for $10 \mathrm{~min}$. Electrophoresis was performed at $93 \mathrm{~V}$ for $1 \mathrm{~h}$ at $25^{\circ} \mathrm{C}$ to identify the amplification fragments.

Immunohistochemical procedure. Following perfusion, the brains were immediately removed, post-fixed overnight in $4 \%$ paraformaldehyde and cryoprotected by infiltration with a sucrose series $(10,20$ and $30 \%)$ at $4^{\circ} \mathrm{C}$. Serial coronal sections of $40 \mu \mathrm{m}$ thickness were obtained on a freezing sliding microtome (Leica Microsystems Ltd., Seoul, Korea) and were collected in 6-well plates. Immunohistochemistry was performed using the free floating method, as described previously (31). The brain areas were identified based on the atlas of the mouse brain by Paxinos and Franklin (32). Briefly, coronal sections were incubated for $48 \mathrm{~h}$ at $4^{\circ} \mathrm{C}$ in rabbit polyclonal antibodies against glycine receptor $\alpha 1 / 2$ (1:2,500; cat. no. ab23809; Abcam, Cambridge, UK) diluted in blocking buffer, containing $1 \%$ bovine serum albumin, $0.3 \%$ Triton $\mathrm{X}-100$ and $1 \%$ normal horse serum. To eliminate peroxidase activity, the sections were treated with $10 \%$ hydrogen peroxide in phosphate-buffered saline (PBS). The sections were incubated with biotinylated goat anti-rabbit IgG antibody (cat. no. BA-1000; Vector Laboratories, Inc., Burlingame, CA, USA) at a dilution of $1: 250$ for $1.5 \mathrm{~h}$ at room temperature, followed by treatment with an avidin-biotin-peroxidase complex (Vectastain ABC mouse Elite kit; Vector Laboratories, Burlingame, CA, USA). Following three washes in PBS, the sections were incubated with 3,3'-diaminobenzidine and hydrogen peroxide in a distilled water solution for $5 \mathrm{~min}$. The sections from each group were stained together to minimize variability. Following additional washes, the sections were mounted onto gelatin coated slides, dehydrated in a solution of increasing ethanol, cleared in xylene and cover slipped with mounting solution (SP15500; Thermo Fisher Scientific, New Jersey, NJ, USA).

Image analysis. A BX51 microscope (Olympus, Tokyo, Japan) was used for the analysis and images were captured using a digital camera system (DP50; Olympus). Staining densities were determined using NIH image program, version 1.44 (Scion Image; Scion Corporation, Bethesda, MA, USA), as described previously (31). Cell counting was performed using a manual cell counting and marking method, and measurement of cell size (area) was performed using ImageJ version 1.44 software (National Institute of Health, Bethesda, MD, USA). The analysis of the slides was performed by an investigator in a blinded manner.

Statistical analysis. Student's t-test was performed using SPSS 17.0 software (SPSS, Inc., Chicago, IL, USA). P<0.05 was considered to indicate a statistically significant difference. The data are expressed as the mean \pm standard deviation. A comparison between + /cir and cir/cir mice was performed for the LSO, SPN and MNTB region from each of the 10 sections 
assessed in each group to measure the GlyR IR, cell counting and cell area.

\section{Results}

Histopathological observations. Intense GlyR IR was observed in all the major nuclei of the SOC in LSO, SPN, MSO and MNTB of +/cir (Fig. 1). GlyR IR was located in the soma, as well as the neuropil, of the LSO region, while it was predominantly located in the soma in the remaining nuclei (Fig. 1A, C and D). Intensely labeled immunoreactive puncta surrounded the soma of these neurons, leaving perikarya unlabeled (Fig. 2). The puncta were restricted to the soma and were not present in the dendrites or the neuropil. Mostly bipolar cells, with eccentric nuclei, were observed in the LSO and MSO region, while the SPN comprised bipolar, as well as a few multipolar neurons (Fig. 2I, K, M and O). The neuropil of the SPN and MSO contained numerous GlyR immunoreactive fibers running in between the stained cells (Fig. $2 \mathrm{~K}$ and $\mathrm{M}$ ). MNTB exhibited a membrane localization staining pattern with punctuate staining, however, dense patchy staining was prominently visible within the soma on the lateral aspect of MNTB.

Compared with $+/$ cir, the cir/cir cells exhibited a very prominent loss of GlyR IR in the soma, as well as the neuropil (Fig. 1B, D and F). Prominent loss of GlyR staining was evident in the neuropil of the LSO of cir/cir, which was markedly more severe in the lateral limb of the LSO compared with the medial limb, while the neurons of the LSO, SPN and MNTB also revealed marked decrement in the GlyR IR. A marked loss of staining was noted in the dendrites of the neurons of the LSO and SPN region (Fig. 2J and K). The GlyR immunoreactive fibers also appeared to be absent in the SPN of the cir/cir cells. A decrease in cell number, as well as cell size, was noted in the different nuclei of the SOC of the cir/cir cells (Fig. 2J, K, L and P).

IR analysis. According to the relative density, the GlyR IR in the SOC region was markedly decreased in all the major nuclei of cir/cir, as compared with $+/$ cir. The GlyR IR in the LSO region was $121.82 \pm 2.40 \mathrm{in}+/$ cir, which was significantly decreased by $7.32 \%$ to $112.89 \pm 2.95$ in $\mathrm{cir} / \mathrm{cir}(\mathrm{P}<0.0001$; Fig. 3A). Compared with $+/$ cir, a significant decrement from $108.35 \pm 3.09$ of $6.2 \%$ was noted in cir/cir $(101.54 \pm 2.74$; $\mathrm{P}<0.0001$; Fig. 3A). A significant decrease in the GlyR IR was also observed from $133.21 \pm 4.15$ in + /cir to $125.71 \pm 4.22$ in cir/cir, which amounted to $7.49 \%$ ( $\mathrm{P}<0.001$; Fig. $3 \mathrm{~A})$. A significant $12.07 \%$ decrease to $101.63 \pm 3.46$ in cir/cir from $113.70 \pm 4.08$ in + /cir was demonstrated $(\mathrm{P}<0.0001)$.

Cell numbers. GlyR immunoreactive cells in the SOC region of $+/$ cir were compared with those from cir/cir. A trend of significant loss of GlyR immunoreactive cells was noted in the cir/cir cells. In the LSO region, a significant $25.30 \%$ decrease from $148.6 \pm 14.80 \mathrm{in}+/$ cir to $111 \pm 12.60 \mathrm{in} \mathrm{cir} / \mathrm{cir}$ $(\mathrm{P}<0.005$; Fig. 3B) was observed. A significant $26.63 \%$ loss of GlyR immunoreactive cells was also noted in the SPN region, decreasing from $48.8 \pm 4.65$ in $+/$ cir to $35.8 \pm 5.71$ in $\mathrm{cir} / \mathrm{cir}$ $(\mathrm{P}<0.005$; Fig. 3B). MSO exhibited a $39 \%$ loss, decreasing from $20 \pm 4.35$ in $+/$ cir to $12.2 \pm 1.92$ in $\mathrm{cir} / \mathrm{cir}(\mathrm{P}<0.01)$.
MNTB, by far, exhibited the least decrement of $16.91 \%$ with $149 \pm 8.68$ in + /cir and $123.8 \pm 7.19$ in cir/cir $(\mathrm{P}<0.001)$, although the IR loss was the most severe in MNTB compared with the other SOC regions (Fig. 3B).

Cell size. The size of the cells present in each nuclei of the SOC was compared between the $+/$ cir and cir/cir groups. No significant difference was observed in the LSO and MSO region of cir/cir, although a trend of decrease was noted in each nuclei. A $2.12 \%$ decrement was observed in the LSO from $233.16 \pm 14.28$ to $228.21 \pm 13.71 \mu \mathrm{m}^{2}$ (Fig. 3C). Similarly, the MSO region also exhibited a $4.94 \%$ decrement from $209.10 \pm 15.21 \mathrm{in}+/$ cir to $198.76 \pm 25.85 \mu \mathrm{m}^{2}$ in cir/cir (Fig. 3C). However, in the SPN, a significant decrease of $4.85 \%$ was noted from $438.70 \pm 19.13$ in $+/$ cir to $417.51 \pm 17.80 \mu \mathrm{m}^{2}$ in cir/cir $(\mathrm{P}<0.01)$. Similarly, principal cells in the MNTB region exhibited a significant $9.44 \%$ decrement in the cir/cir as compared with +/cir from $414.35 \pm 23.18$ to $375.20 \pm 34.72 \mu \mathrm{m}^{2}$, respectively $(\mathrm{P}<0.01$; Fig. $3 \mathrm{C})$.

\section{Discussion}

The present study revealed a decrease in the GlyR IR, as well as GlyR immunoreactive cell number and cell size in the SOC nuclei of cir/cir when compared with $+/$ cir. This is consistent with previous reports of deafness-associated decreases in the Gly immunoreactive cells in the SOC (25).

A decrease in the GlyR in cir/cir may be a consequence of the decrease in the glycine levels, which may possibly lower the immunocytochemical detection or it may be due to a physical reduction in the number of the GlyR immunoreactive cells, as well as the decrease in the cell size, as noted in the present study. This may be the result of an activity-dependent decrease following deafness, associated with decreased activity. Pruning of glycinergic terminals in LSO and MSO (33) due to experience-dependent plasticity is also possible, particularly due to sustenance of glutamatergic transmission in cir/cir, although it has been hypothesized to be a temporary phase (28). Readjustments in the location of glycine immunoreactive terminals with terminals moving from soma to dendrites has been previously reported (34), however the loss of dendritic staining in the cir/cir firmly rejects this hypothesis. Furthermore, even without the quantitative assessment of the GlyR immunoreactive puncta in the present study, a qualitative decrement was noted in all SOC nuclei. A qualitative and quantitative study of glycine immunoreactive axo-somatic puncta may assist in clarifying these issues.

Bilateral deafness, induced by intrascalar injection of neomycin in rats, causes a significant decrease in glycine IR in the nuclei of SOC (25). A significant decrement in the number of glycine immunoreactive puncta on the somata of principal cells was reported, which may be due to transneuronal degeneration, as observed in the SOC following cochlear damage $(3,35)$. However, unilateral deafening produced no changes in glycine release in LSO or MNTB, however, this was noted in the cochlear nucleus (CN) (21). Bilateral deafness, as in cir/cir, caused a significant decrease of GlyR in the SOC and $\mathrm{CN}$ (unpublished data). This difference may be contributed to the bilateral innervation received by the SOC nuclei from both ipsilateral and contralateral CNs. Cochlear ablation also 

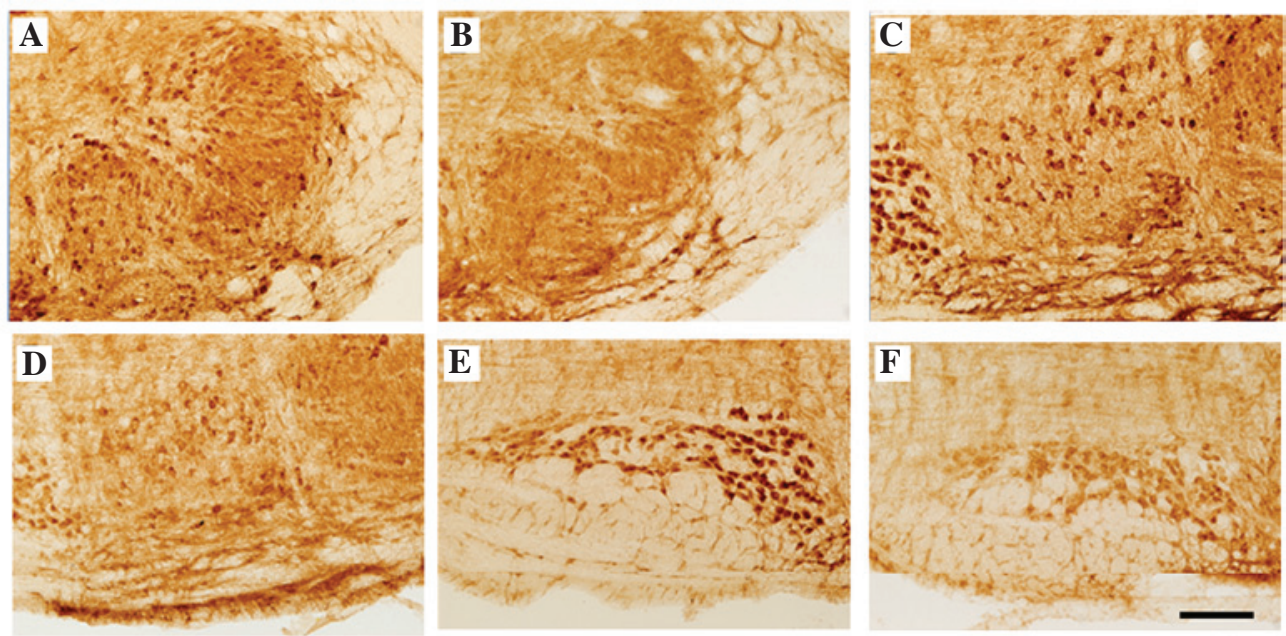

Figure 1. Immunohistochemical localization of GlyR $\alpha 1$ and $\alpha 2$ IR in coronal sections through the SOC comprising (A and B) LSO, (C and D) SPN and MSO, and (E and F) MNTB of heterozygote (A, C and E) and homozygote (B, D and F) circling mice. GlyR IR was observed in the neurons and neuropil of (A and B) LSO, (C and D) SPN and MSO, and (E and F) MNTB of +/cir and cir/cir mice. Compared with +/-, loss of GlyR IR was observed in all nuclei and neuropil of the cir/cir mice. (Scale bar, $100 \mu \mathrm{m}$ ). SOC, superior olivary complex; LSO, lateral superior olive; SPN, superior paraolivary nucleus; MSO, medial superior olive; MNTB, medial nucleus of the trapezoid body; GlyR, glycine receptor; IR, immunoreactivity.

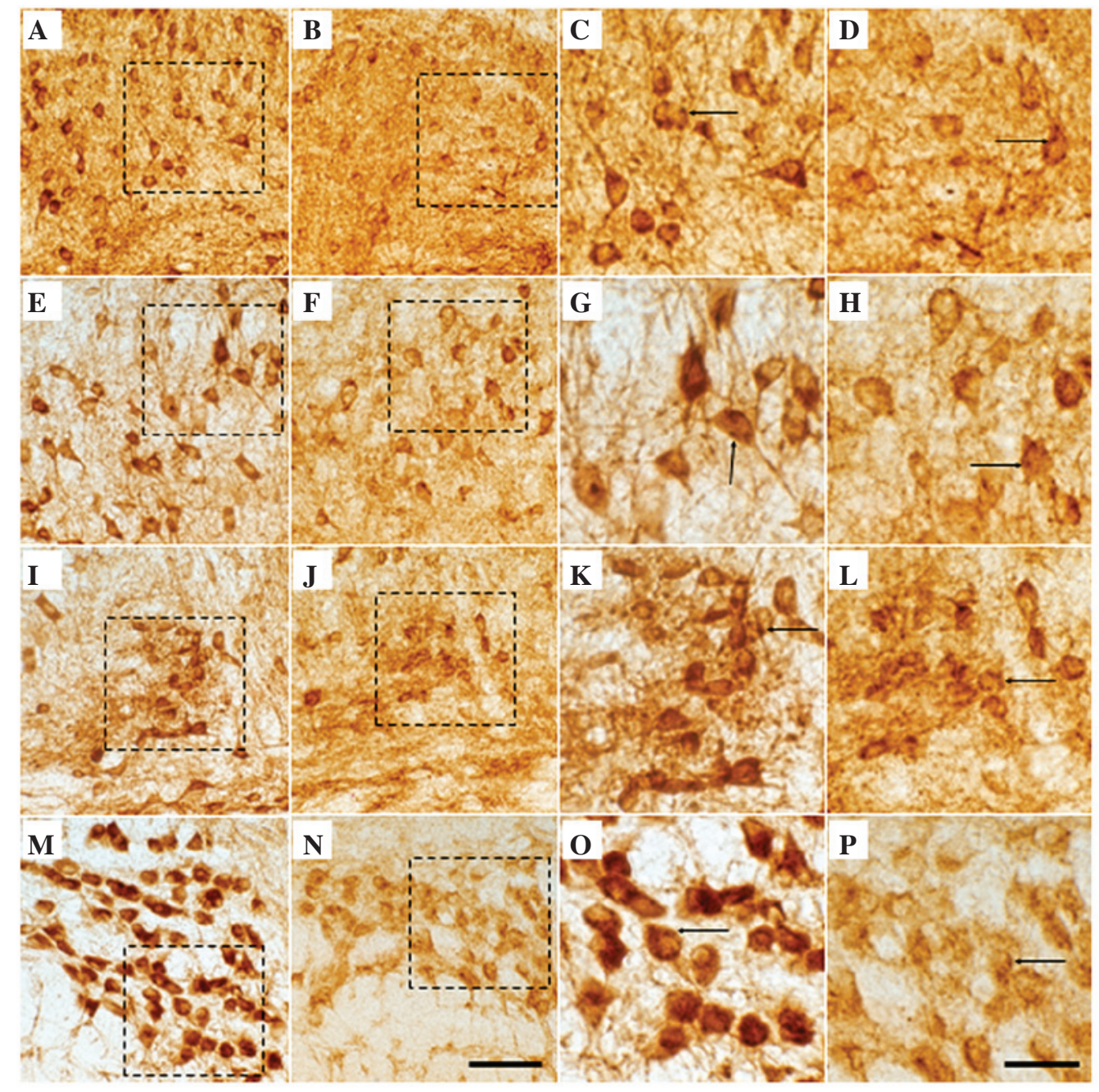

Figure 2. Magnified image of GlyR $\alpha 1$ and $\alpha 2$ IR in coronal sections through the SOC comprising (A, B, I and J) LSO, (C, D, K and L) SPN, (E, F, M and N) MSO and (G, H, O and P) MNTB of +/cir (A, C, E, G, I, K, M and O) and cir/cir (B, D, F, H, J, K, L and P) mice. Scattered highly GlyR IR was noted in all nuclei of SOC. Puncta (arrows) possibly indicate presynaptic terminals. A loss of GlyR immunoreactive cells was noted in the (B and J) LSO, (D and K) SPN, (F and N) MSO and (H and P) MNTB of cir/cir mice. A decrease in the size of the soma of cir/cir mice was observed, compared with +/cir mice (Scale bar, A-H, $50 \mu \mathrm{m}$; I-P, $10 \mu \mathrm{m}$.). SOC, Superior Olivary Complex; LSO, Lateral Superior Olive; SPN, Superior Paraolivary Nucleus; MSO, Medial Superior Olive; MNTB, Medial Nucleus of the Trapezoid Body; IR, immunoreactivity. 
A

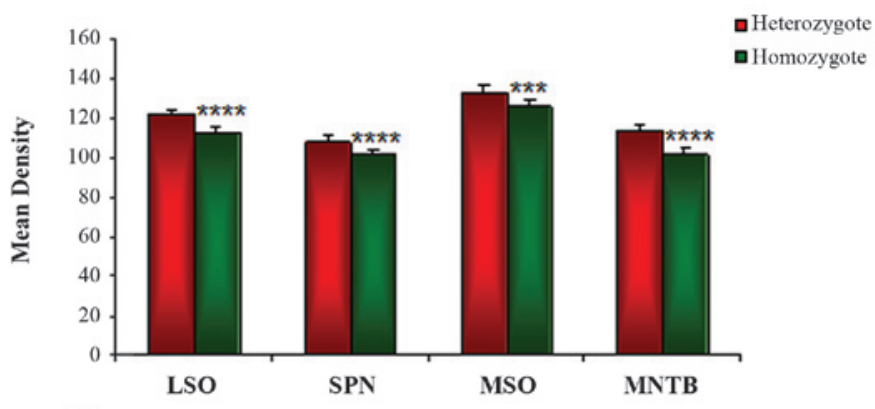

$\mathbf{B}$

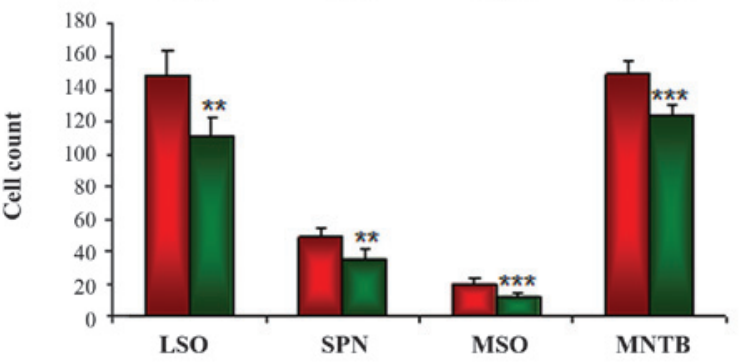

C

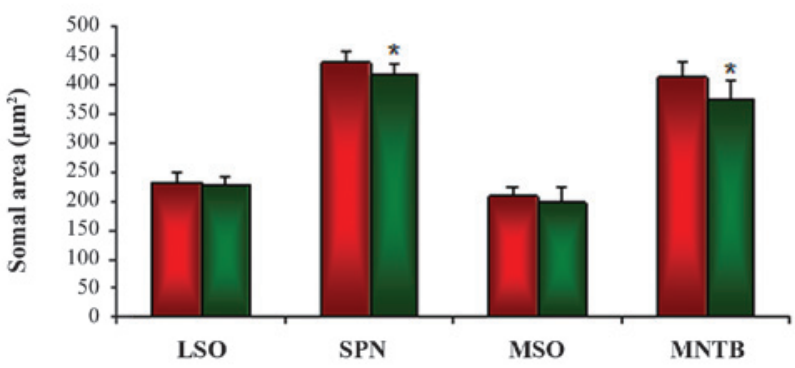

Figure 3. Graph demonstrating the image analysis of (A) relative density, (B) cell number and (C) cell size of glycine receptor $\alpha 1$ and 2 in the various different regions (Lateral Superior Olive, Superior Paraolivary Nucleus, Medial Superior Olive and Medial Nucleus of the Trapezoid Body) of the superior olivary complex of adult heterozygous (+/cir), and homozygous (cir/cir) circling mice $\left({ }^{*} \mathrm{P}<0.01,{ }^{* * *} \mathrm{P}<0.001,{ }^{* * * *} \mathrm{P}<0.005\right.$ and ${ }^{* * * *} \mathrm{P}<0.0001$, compared with the heterozygote).

results in a decrease in glycine release in the CNs $(4,21,36)$, suggesting that the decreased inhibition following deafness may be associated with the decrease in glycine. Previous studies have suggested deafness as a factor influencing the intracellular pathways modulating neurotransmitters and their release.

The present study revealed a significant percentage decrease of GlyR IR, as well as in cell number and cell size, in the SOC. This decrement was higher for LSO and MNTB in all three aspects, which is particularly important, taking into consideration the importance of MNTB-LSO synapses. SOC uses glycine as major inhibitory neurotransmitter with the majority of the glycinergic pathway originating in the MNTB (37), while balance in the LSO between glycinergic inhibition and glutamatergic excitation from the $\mathrm{CN}$ is important for detection of interaural level differences, which appears to be imbalanced in cir/cir due to sustained glutamatergic transmission (28). Indeed, deafness-associated changes in the potential regulators of transmitter release has been reported in the auditory brainstem $(10,38)$ and is supported by the immunohistochemical results of the present study.

The LSO receives excitatory projections from ipsilateral and inhibitory from contralateral projections (39). Inhibitory projection arises from homogeneous glycinergic nuclei, MNTB projects topographically along the LSO frequency axis, while the excitatory projection emerges from $\mathrm{CN}$ is glutamatergic whose tonotopic projection matches perfectly with inhibitory projection from MNTB, allowing LSO neurons to respond selectively to interaural level differences. The inactivity of GlyR led to a significant decrease in the number of cell surface receptor clusters on cultured spinal cord neurons (40), suggesting that the loss of the glycinergic inhibitor induces change/redistribution of postsynaptic membrane GlyRs. Hearing loss leads to severe long term weakening of glycinergic synaptic inhibition in the LSO, contributing to the downregulation of synaptic release of glycine in dorsal $\mathrm{CN}$ and downregulation of postsynaptic GlyR activity in the LSO (5). Hence, a decrease in the GlyR IR in the neurons and neuropil, and a decrease in cell number and size, as noted in the cir/cir, may lead to a decrease in inhibitory transmission leading to profound changes in the functional properties in the SOC nuclei particularly at LSO and MNTB. The data from electrophysiological experiments and electron microscopy in adult circling mice may assist in further elucidating the association between the GlyR and neural function associated with deafness.

\section{Acknowledgements}

The present study was supported by the Basic Science Research Program, through the National Research Foundation of Korea funded by the Ministry of Education (grant no. NRF-2011-0011885) and the Basic Science Research Program through the National Research Foundation of Korea 
(NRF) funded by the Ministry of Science, ICT \& Future Planning (grant no. NRF-2014R1A2A2A04003616).

\section{References}

1. Lee JW, Lee EJ, Hong SH, Chung WH, Lee HT, Lee TW, Lee JR, Kim HT, Suh JG, Kim TY and Ryoo ZY: Circling mouse: Possible animal model for deafness. Comp Med 51: 550-554, 2001.

2. Syka J: Plastic changes in the central auditory system after hearing loss, restoration of function and during learning. Physiol Rev 82: 601-636, 2002.

3. Potashner SJ, Suneja SK and Benson CG: Regulation of $\mathrm{D}$-aspartate release and uptake in adult brain stem auditory nuclei after unilateral middle ear ossicle removal and cochlear ablation. Exp Neurol 148: 222-235, 1997.

4. Potashner SJ, Suneja SK and Benson CG: Altered glycinergic synaptic activities in guinea pig brain stem auditory nuclei after unilateral cochlear ablation. Hear Res 147: 125-136, 2000.

5. Milbrandt JC, Hunter C and Caspary DM: Alterations of GABAA receptor subunit mRNA levels in the aging Fischer 344 rat inferior colliculus. J Comp Neurol 379: 455-465, 1997.

6. Nakagawa H, Sato K, Shiraishi Y, Kuriyama H and Altschuler RA: NMDAR1 isoforms in the rat superior olivary complex and changes after unilateral cochlear ablation. Brain Res Mol Brain Res 77: 246-257, 2000.

7. Von Hehn CA, Bhattacharjee A and Kaczmarek LK: Loss of Kv3.1 tonotopicity and alterations in cAMP response element-binding protein signaling in central auditory neurons of hearing impaired mice. J Neurosci 24: 1936-1940, 2004.

8. Garcia MM, Edward R, Brennan GB and Harlan RE: Deafferentation induced changes in protein kinase $C$ expression in the rat cochlear nucleus. Hear Res 147: 113-124, 2000.

9. Idrizbegovic E, Bogdanovic N and Canlon B: Modulating calbindin and parvalbumin immunoreactivity in the cochlear nucleus by moderate noise exposure in mice. A quantitative study on the dorsal and posteroventral cochlear nucleus. Brain Res 800: 86-96, 1998.

10. Suneja SK and Potashner SJ: ERK and SAPK signaling in auditory brainstem neurons after unilateral cochlear ablation. J Neurosci Res 73: 235-245, 2003.

11. Bledsoe SC Jr, Nagase S, Miller JM and Altschuler RA: Deafness induced plasticity in the mature central auditory system Neuroreport 7: 225-229, 1995.

12. Nagase S, Miller JM, Dupont J, Lim HH, Sato K and Altschuler RA: Changes in cochlear electrical stimulation induced Fos expression in the rat inferior colliculus following deafness. Hear Res 147: 242-250, 2000.

13. Legendre P: The glycinergic inhibitory synapse. Cell Mol Life Sci 58: 760-793, 2001

14. Caspery DM: Electrophysiological studies of glycinergic mechanisms in auditory brainstem structures. In: Ottersen OP, Storm-Mathisen J (Eds.), Glycine Neurotransmission. Chichester: Wiley, pp453-pp483, 1990.

15. Wenthold RJ, Huie D, Altschuler RA and Reeks KA: Glycine immunoreactivity localized in the cochlear nucleus and superior olivary complex. Neuroscience 22: 897-912, 1987.

16. Wenthold RJ and Hunter C: Immunocytochemistry of glycine and glycine receptors in the central auditory system. In: Ottersen OP, Storm-Mathisen J (Eds.), Glycine Neurotransmission, Chichester: Wiley, pp391-pp416, 1990.

17. Vater M, Habbicht H, Kössl M and Grothe B: The functional role of GABA and glycine in monaural and binaural processing in the inferior colliculus of horseshoe bats. J Comp Physiol A 171: $541-553,1992$

18. Kavanagh GL and Kelly JB: Midline and lateral feld sound localization in the ferret (MustelaPutorius): Contribution of the superior olivary complex. J Neurophysiol 67: 1643-1658, 1992.
19. O'Neill WE, Zettel ML, Whittemore KR and Frisina RD: Calbindin D-28k immunoreactivity in the medial nucleus of the trapezoid body declines with age in C57BL/6, but not CBA/CaJ, mice. Hear Res 112: 158-166, 1997.

20. Banks MI and Smith PH: Intracellular recordings from neurobiotin-labeled cells in brain slices of the rat medial nucleus of the trapezoid body. J Neurosci 12: 2819-2837, 1992.

21. Suneja SK, Benson CG and Potashner SJ: Glycine receptors in adult guinea pig brain stem auditory nuclei: Regulation after unilateral cochlear ablation. Exp Neurol 154: 473-488, 1998.

22. Suneja SK, Potashner SJ and Benson CG: Plastic changes in glycine and GABA release and uptake in adult brain stem auditory nuclei after unilateral middle ear ossicle removal and cochlear ablation. Exp Neurol 151: 273-288, 1998.

23. Willott JF and Turner JG: Neural plasticity in the mouse inferior colliculus: Relationship to hearing loss, augmented acoustic stimulation and prepulse inhibition. Hear Res 147: 275-281, 2000.

24. Krenning J, Hughes LF, Caspary DM and Helfert RH: Age-related glycine receptor subunit changes in the cochlear nucleus of Fischer-344 rats. Laryngoscope 108: 26-31, 1998.

25. Buras ED, Holt AG, Griffith RD, Asako M and Altschuler RA: Changes in glycine immunoreactivity in the rat superior olivary complex following deafness. J Comp Neurol 494: 179-189, 2006.

26. Kandler K and Friauf E: Development of glycinergic and glutamatergic synaptic transmission in the auditory brainstem of perinatal rats. J Neurosci 15: 6890-6904, 1995.

27. Gillespie DC, Kim G and Kandler K: Inhibitory synapses in the developing auditory system are glutamatergic. Nat Neurosci 8: 332-338, 2005.

28. Hong SH, Kim MJ and Ahn SC: Glutamatergic transmission is sustained at a later period of development of medial nucleus of the trapezoid body-lateral superior olive synapses in circling mice. J Neurosci 28: 13003-13007, 2008.

29. Schwartz IR: The superior olivary complex and lateral lemniscal nuclei. In: (Webster B, Popper AN, Fay RR (EDs.), The Mammalian Auditory Pathways: Neuroanatomy New York: Springer, pp117-pp167, 1990.

30. Friauf E, Hammerschmidt B and Kirsch J: Development of adult-type inhibitory glycine receptors in the central auditory system of rats. J Comp Neurol 385: 117-134, 1997.

31. Maskey D, Kim M, Aryal B, Pradhan J, Choi IY, Park KS, Son T, Hong SY, Kim SB, Kim HG and Kim MJ: Effect of 835 MHz radiofrequency radiation exposure on calcium binding proteins in the hippocampus of the mouse brain. Brain Res 1313: 232-241, 2010.

32. Paxinos G and Franklin KBJ: The Mouse Brain in Stereotaxic Coordinates (Second edition). San Diego: Academic Press, 2001.

33. Sanes DH and Friauf E: Development and influence of inhibition in the lateral superior olivary nucleus. Hear Res 147: 46-58, 2000.

34. Kapfer C, Seidl AH, Schweizer H and Grothe B: Experience-dependent refinement of inhibitory inputs to auditory coincidence-detector neurons. Nat Neurosci 5: 247-253, 2002.

35. Kim J, Morest DK and Bohne BA: Degeneration of axons in the brain stem of the chinchilla after auditory overstimulation. Hear Res 103: 169-191, 1997.

36. Asako M, Holt AG, Griffith RD, Buras ED and Altschuler RA: Deafness-related decreases in glycine-immunoreactive labeling in the rat cochlear nucleus. J Neurosci Res 81: 102-109, 2005.

37. Spirou GA and Berrebi AS: Glycine immunoreactivity in the lateral nucleus of the trapezoid body of the cat. J Comp Neurol 383: 473-488, 1997.

38. Zhang S and Oertel D: Neuronal circuits associated with the output of the dorsal cochlear nucleus through fusiform cells. J Neurophysiol 71: 914-930, 1994.

39. Boudreau JC and Tsuchitani C: Cat superior olive s-segment cell discharge to tonal stimulation. Contrib Sens Physiol 4: 143-213, 1970.

40. Lévi S, Vannier C and Triller A: Strychnine-sensitive stabilization of postsynaptic glycine receptor clusters. J Cell Sci 111: 335-345, 1998. 